\title{
Kırklareli merkez örnekleminde Z kuşağı gençlerinin sosyal medyadaki yeni kelimeleri kullanım alışkanlıkları üzerine nicel bir yaklaşım
}

Zehra ŞAFAK'

\section{Mertcan BİLGINSOY²}

\begin{abstract}
APA: Şafak, Z. (2019). Kırklareli merkez örnekleminde Z kuşağı gençlerinin sosyal medyadaki yeni kelimeleri kullanım alıskanlıkları üzerine nicel bir yaklaşım. RumeliDE Dil ve Edebiyat Araşttrmaları Dergisi, (Ö5), 125-136. DOI: 10.29000/rumelide.606082.
\end{abstract}

\section{$\ddot{O} \mathbf{z}$}

Kuşak kuramına göre, aynı dönemlerde doğan, büyüyen, aynı yaş gruplarında yer alan bireylerin aynı davranış özelliklerini göstermesi beklenir. Teknolojik, ekonomik, siyasal ve sosyal köklü değişimler kuşakların farklı olmasının temel nedenlerindendir. Her kuşak kendi modasını, kendi yaşam tarzını meydana getirir, önceliklerini belirler, dönemin teknolojik gelişmelerini takip etmeye çalışır. Bütün bu gelişmeler o kuşağa ait yeni kelimelerin ortaya çıkmasına ve bu yeni kelimelerin sık kullanılmasına neden olmaktadır. Bu makale Z kuşağının dil kullanımıyla ilgili olup, bu kuşağın kullandığı yeni kelimelerin kullanım sıklığını incelemektedir. Saha çalışmalarında öğrencilerin Facebook, Twitter, WhatsApp gibi sosyal medya araçlarında kullandıkları yeni kelimeler gözlem ve mülakat tekniklerine bağlı kalınarak tespit edilmiştir. Bu kelimelerden bir ölçek geliştirilmiştir. Ölçek, oranlı küme örnekleme yöntemiyle Kırklareli merkezde farklı okullarda okuyan 9, 10, 11 ve 12. sinıflardan toplam 100 öğrenciye uygulanmıştır. Uygulamadan elde edilen verilerden öğrencilerin farklı medya uygulamalarını kullandıkları ve bu uygulamalar ile uygulamanın ortaya çıkardı̆̆ı yeni kelimeler arasında pozitif bir ilgileşim olduğu, ayrıca İngilizceden kısmi ve tam ödünçlemelerin Türkçe yapılarla türetilen kelimelerden daha çok olduğu ve daha sık kullanıldıkları tespit edilmiştir.

Anahtar kelimeler: Neolojizm, yeni kelime, sosyal medya, iletişim teknolojileri.

\section{$Z$ generation of young people in social media usage patterns of neologisms a quantitative approach in the sample Kurklareli province center}

\begin{abstract}
According generation theory; the persons who born and growing in the same period is expected to show the same behavior characteristics. Technological,economic, potical and social changes are the main reasons for the generations. Every genaration creates its own fashion, creates its own life style, determines its priority, tries to follow technological developments of the period, needs to adopt to its age groups. All these development cause to rise the new words of that generations. These new words used by the $\mathrm{Z}$ generation born after 2000 and unique neologisms. The aim of our study is to answer the following problems releated to the neologisms used by young people between the age of 14-18: Which neologisms (new words) are used by young people in social media? In which age groups are these new words used and how often do they used? What are the structural conditional of these new detected words? Are there diffrences in terms of frequency and form among girls and boys in use of
\end{abstract}

1 YL Öğrencisi, Tekirdağ Namık Kemal Üniversitesi, Sosyal Bilimler Enstitüsü (Tekirdağ, Türkiye), 777zehra@gmail.com, ORCID ID: 0000-0002-2500-373X [Makale kaylt tarihi: 22.06.2019-kabul tarihi: 18.08.2019; DOI: 10.29000/rumelide.606082] 
$\mathbf{Z}$ generation of young people in social media usage patterns of neologisms a quantitative approach in the sample Kurklareli province center / Z. Şafak (p. 125-136)

\begin{abstract}
neologisms? As a method: samples were selected randomly as a total of 100 students and half of them were girls, half of them boys. social tools such as Facebook, Twitter, whatsapp the neology used in the students' speeches were determined. These words were surveyed and presented as a questionnare to 100 students, were asked questions about their preferences.In the conclusion section according to the implications solution suggestions that can be used in educational institutions are presented.
\end{abstract}

Keywords: Neologism, new word, social media, communication technologies.

\title{
Giriş
}

Teknolojik, ekonomik, siyasal ve sosyal köklü değişimler kuşakların farklı olmasının temel nedenlerindendir. Her kuşak kendi modasını, kendi yaşam tarzını meydana getirir, önceliklerini belirler, dönemin teknolojik gelişmelerini takip etmeye çalışır. Bütün bu gelişmeler o kuşağa ait yeni kelimelerin ortaya çımasına ve bu yeni kelimelerin sık kullanılmasına neden olmaktadır. Günümüzde en hızlı gelişme iletişim ve bilişim teknolojilerinde gözlemlenmektedir. Gelişen mobil iletişim teknolojileri ve uygulamalar yeni kelimelerin ortaya çıkmasına neden olmaktadır. Bu yeni kelimeler 2000 yllından sonra doğan Z kuşağının kullandığı ve kendi diline özel yeni kelimelerdir. Z kuşağı oldukça erken yaşta iletişim teknolojileriyle tanışmakta ve yoğun bir şeklide bu teknolojileri kullanmaktadır. Bu gençlerin kullandığı kelime dağarcığına mobil teknolojileri ile ilgili yeni kelimeler girmekte ve bu kelimeler diğer kuşaklar tarafından bilinmemekte veya az bilinmektedir.

Günümüzde internet ve mobil teknolojilerin ucuzlaması kullanımlarının yaygınlaşmasına neden olmaktadır. Bu uygulamalarla birlikte yeni kelimeler de ortaya çıkmaktadır.

\section{Kavramsal ve kuramsal çerçeve}

Türk Dil Kurumu Türkçe Sözlüğünde neoloji kelimesi mevcut değildir, neolojizm kelimesi ise "yeni üretilen söz” (Eren, 1988), TDK’nin çevrimiçi sözlügünde ise neolojizm “türenti” (http://sozluk.gov.tr/) şeklinde verilmektedir. Fransızcada yeni kelime türetmeyle ilgili neoloji (néologie) ve neolojizm (néologisme) şeklinde iki terim kullanılmaktadır. Bu terimler Grand Larousse de la Langue Française adlı sözlükte neoloji kelimesi yeni kelimelerin oluşturulması, neolojizm ise yeni kelimelerin kullanıma alınması diğer bir tanımı da yeni oluşturulan kelime veya yeni alıntı kelime anlamındadır (Şafak, 2018).

Neoloji ve neolojizm arasındaki farkı şu şekilde ifade etmek mümkündür. Neolojiyi meydana getiren süreç (procès) yöntemleri de içermektedir. Neolojizm ise bu süreçlerin ve yöntemlerin sonucunda oluşan üründür (produit). Bu ürün yani yeni kelime toplum tarafında benimsenir ise başarılı olabilir. Eğer toplum tarafında benimsenmez ise başarısız da olabilmektedir (Moeschler, 1974).

TDK çevrimiçi sözlüğünde, kuşak kavramı aşă̆ı yukarı aynı yıllarda doğmuş aynı çağın koşullarını, dolayısıyla birbirine benzer sıkıntıları yazgıları yaşamış, benzer ödevlerle yükümlü kişiler topluluğu olarak tanımlanmaktadır. Ayrıca toplum biliminde yaklaşık yirmi beş, otuz yıllık yaş kümelerinin oluşturulan bireyler öbeği, öbek, nesil, batın, jenerasyon şeklinde tanımlanmaktadır (http://sozluk.gov.tr/).

Kuşakları çalışan bilim insanları farklı tarih aralıklarına göre kuşakları sınıflandırmışlardır. Örneğin DeVaney, 1925-1945 yılları arasında doğan kuşağa "Sessiz Kuşak", 1945-1964 yılları arasında doğan kuşağa "Bebek Patlaması Kuşağı”, 1965-1979 yılları arasında doğan kuşağa “X Kuşă̆ı”, 1980-1999 yılları 
arasında doğan kuşağa "Y Kuşağı, 2000 ve sonrası doğan kuşağa "Z Kuşağı" adlandırmalarını getirmiştir. DeVaney tarafından yapılan bu sınıflandırma en çok kabul gören sınıflandırmadır (Özden, 2019).

Z kuşağı birçok bilim insanı tarafindan farklı adlandırılmıştır; Twenge, Campel, Hoffman ve Lance’a göre Z kuşağı şeklinde tanımlanan bu kuşak Oblinger'e göre "Net kuşă̆ı”, Prensky'e göre "Dijital yerliler" olarak tanımlanmaktadır (Erten, 2019).

Z kuşağının özeliklerini şu şekilde sıralamak mümkündür (Altunbay ve Bıçak, 2018):

a. Tablet, bilgisayar ve akıllı telefonlar gibi teknolojik aygıtlar yaşantılarının birer vazgeçilmezidir.

b. Diğer kuşaklara kıyasla teknolojiyi çok daha iyi kullanırlar.

c. Önceki kuşaklarla kıyaslandıklarında bilgiye daha çabuk ulaşmaktadırlar ve bilgiyi daha çabuk yorumlayabilmektedirler.

d. Yalnız yaşamayı tercih etmektedirler.

e. Hırslı ve materyalist düşüncelere sahiptirler.

f. Dışarıdan ziyade ev ofis ortamında daha çok zaman geçirirler.

g. Sosyal medya yoluyla en çabuk ve kolay sosyalleşirler.

h. Yenilik üretmek ve yeniliği kullanmaktan haz duyarlar.

i. Her şeye çabuk ulaşmayı ve hızlı tüketmeye isteklidirler.

j. Aynı anda birden fazla iş yapabilirler, örneğin ders çalışırken tabletten oyun oynayan ve televizyonda film izleyip sahneler arasında kusursuz bir şeklide ilişki kurabilmektedirler.

k. Kendi istedikleri zaman ve mekânda öğrenme konusunda istek gösterirler.

\section{Kuşak ve Dil}

Her kuşak kendi söz dağarcı̆̆ıyla doğar, kuşağın ortaya çıkardığı yeni bilimsel buluşlar ve teknolojik icatlar kuşakla beraber yeni kelimelerin (neolojizm) ortaya çıkmasına neden olur. Her doğan yeni kuşakla birlikte eski kuşağın kullandığı bazı sözcüklerin kullanımı azalır ve zaman içerisinde bu sözcükler unutulur, hatta yeni kuşak tarafından bilinmez. Örneğin (1945-1964) "Bebek Patlaması" kuşağının kelimeleri plak, gramofondur. Teyp, kasetçalar, kaset, walkman, video, (1969-1979) "X Kuşağın" kelimeleridir. İnternet, ICQ, Ipod, SMS, e-posta, disket, CD, DVD, AltaVista (1980-1999) "Y Kuşağın" kelimeleridir. Bellek, flaş, mikro SD kart, android, facebook, google, twitter, instagram (2000 ve sonrası) "Z kuşağın” kelimeleridir.

Z kuşağının dil kullanımındaki diğer bir önemli özelliği de kendini sosyal medya aracılı̆̆ıyla daha kolay ifade etmesi ve bu şekilde iletişim kurmasıdır. Z kuşağında doğanlar dil kullanımında uzun kelimeler ve cümleler yerine kısaltmaları kullanmayı tercih ederler, örneğin slm, mrb gibi. Bu kuşak yoğun bir şekilde kelime yerine emojiler ve işaretler kullanma konusunda son derece isteklidir.

\section{Araştırmanın amacı}

Bu araştırmada Z kuşağına dâhil olan ve Kırklareli il merkezinde değişik okullarda öğrenim gören 13-18 yaş arası gençlerin sosyal medyada kullandıkları dil incelenmiştir. Araştırmada aşağıdaki sorulara cevap aranmıştır:

-13-18 yaş arası gençler sosyal medya kullanırken hangi yeni kelimeleri kullanmaktadır? 
-Saha araştırmalarında tespit edilen yeni kelimelerin türetme biçimine göre durumları nasıldır?

-Tespit edilen kelimelerin İngilizceden ödünçleme ve Türkçe kökenli olanların kullanım sıklıkları nasıldır?

-Aynı anlama gelen ve aynı sosyal uygulamalarda kullanılan Türkçe ve yabancı kökenli kelimelerin kullanım sıklıkları nasıldır?

-Tespit edilen kelimelerin güncel olan TDK çevrimiçi sözlüğ̈̈ne girme oranları nedir?

-Yeni kelimeler hangi anlamda kullanılmaktadır?

\section{Veri toplama ve işleme yöntemi}

Araştırmacıların öğretmen ve öğrenci olması sebebiyle gözlem yapılarak okul ortamında, öğrencilerin konuşmaları esnasında sorulacak 50 adet kelimenin derlemesi yapıldı. Bu kelimeler ölçek hâline getirildi, 5’li Likert ölçeğine göre 1- Anlamını bilirim ve sık kullanırım. 2- Anlamını bilirim ve bazen kullanırım. 3- Anlamını bilirim fakat kullanmam. 4- Anlamını bilmem fakat kullanırım. 5- Anlamını bilmem ve hiç kullanmam, şeklinde ölçütler oluşturuldu. Daha sonra farklı öğrenci profiline sahip okullar tespit edildi. Bu okulların seçiminde LGS okul giriş puanları dikkate alındı. Okullar, Kırklareli Fen Lisesi (KFL), Kırklareli Anadolu Lisesi (KAL), Kırklareli Atatürk Anadolu Lisesi (KAAL), Kurklareli İmam Hatip Lisesi (KİHL), Kocahıdır Meslek ve Teknik Anadolu Lisesi (KMTAL) şekilde belirlendi. Daha sonra her sınıf seviyesinden 5'er öğrenci seçilerek her sınıf seviyesi bir küme kabul edildi, bu durumda oranlı küme örnekleme yöntemi seçildi. Sahada tespit edilen kelimelerin kullanımıyla Google Forum uygulaması yapıldı. Sonuçlar SPSS 25 programında işlendi.

50 maddelik ölçek okullarda toplamda 100 öğrenciye uygulanması neticesinde ölçeğin faktörel yapısını belirlemek için SPSS 25 programında ölçeğin geçerlilik durumunu da gösteren açıklayıcı faktör analizi yapılmıştır. Sonuçlar şu şekildedir:

Tablo 1.

\section{Geçerlilik Analizi}

KMO andBartlett's Test

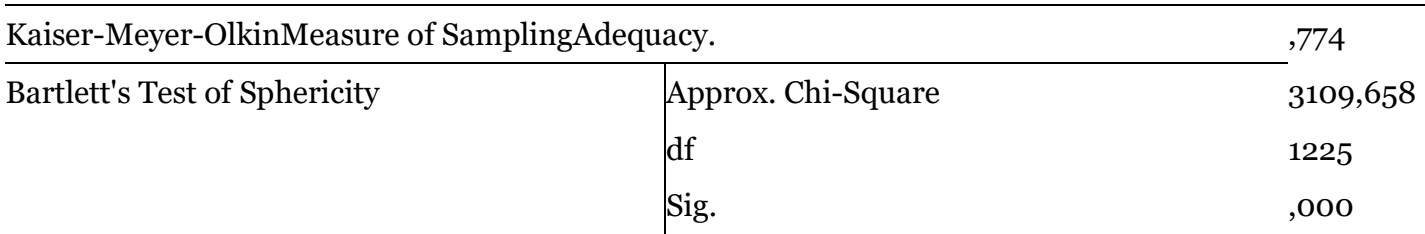

(Tablo 1) Kaiser-Meyer-Olkin istatistiğinin değeri 0,774 çıkması ve bu değerin 0,50 büyük olması örneklem sayısının yeterli olduğunu göstermektedir. Ki kare değeri 3109,658 olarak hesaplanmış olup, Sig<0,05 olduğundan faktör analizi için verilerin uygun olduğu görülmektedir (Can, 2017). 50 maddenin faktör yük değerli o,646 en düşük, en yükseği de 878 olarak hesaplanmıştır. Bu değerlerin o,30 büyük olması sebebiyle herhangi bir maddenin (kelimenin) ölçekten çıkarılmasına gerek yoktur (Kuyucu, 2014).

Kelime ölçeğinin güvenirlik analizi yapılarak sonuçları şu şekildedir: 
Tablo 2.

\begin{tabular}{|c|c|c|c|}
\hline \multicolumn{4}{|c|}{ Güvenirlik Analizi } \\
\hline Cronbach's Alpha & $\begin{array}{l}\text { Cronbach's Alpha } \\
\text { StandardizedItems }\end{array}$ & Based & on $\mathrm{N}$ of Items \\
\hline ,944 & ,942 & & 50 \\
\hline
\end{tabular}

Çalışmada sorulan 50 kelimenin Gronbach’s Alpha değeri 0,944 olarak hesaplamıştır, bu değer ne kadar 1 değerine yaklaşırsa ölçme o kadar hatadan arınık demektir (Can, 2017). 0,944 değerine göre ölçek güvenilirdir ( Tablo 2).

Örneklemlerle ilgili sıklık analizleri şu şekildedir:

Tablo 3.

\begin{tabular}{lcc}
\hline \multicolumn{2}{l}{ Yaş Grubuna Göre Örneklem Sayıları } & \\
\hline Yaş Grubu & Öğrenci Sayısı (n) & Oran \\
$13-14$ & 4 & $\% 4$ \\
$15-16$ & 46 & $\% 46$ \\
$17-18$ & 50 & $\% 50$ \\
\hline Toplam & 100 & $\% 100$ \\
\hline
\end{tabular}

Tablo 4 .

\begin{tabular}{lll}
\hline İkamet Yerine Göre Örneklem Sayıları & \\
\hline İkamet yeri & Öğrenci Sayısı (n) & Oran \\
İl Merkezi & 72 & $\% 72,0$ \\
İlçe Merkezi & 13 & $\% 13,0$ \\
Kasaba & 5 & $\% 5,0$ \\
Köy & 10 & $\% 10,0$ \\
\hline Toplam & 100 & $\% 100,0$ \\
\hline
\end{tabular}

Tablo 5.

\section{Cinsiyete Göre Örneklem Dağılımı}

\begin{tabular}{lcl}
\hline Cinsiyet & Öğrenci Sayısı (n) & Oran \\
Erkek & 50 & $\% 50,0$ \\
Kız & 50 & $\% 50,0$ \\
Toplam 100,0 & & $\% 100,0$
\end{tabular}


$\mathbf{Z}$ generation of young people in social media usage patterns of neologisms a quantitative approach in the sample Kurklareli province center / Z. Şafak (p. 125-136)

\begin{tabular}{lll}
\hline Tablo 6. & \\
\hline Baba Ĕ̆itim Durumuna Göre Örneklem Dağılımı & \\
\hline Baba Ĕ̆itim Durumu & Sıklık Dağılımı (n) & Oran \\
Belirtilmemiş & 1 & $\% 1,00$ \\
İlkokul & 20 & $\% 20,0$ \\
Ortaokul & 34 & $\% 34,0$ \\
Lise & 22 & $\% 22,0$ \\
Üniversite & 23 & $\% 23,0$ \\
\hline Toplam & 100 & $\% 100,0$ \\
\hline
\end{tabular}

Tablo 7.

\begin{tabular}{lll}
\hline Anne Ĕ̆itim Durumuna Göre Örneklem Dağılımı & \\
\hline Anne Eğitim Durumu & Sıklık Dağlımı (n) & Oran \\
İlkokul & 37 & $\% 37,0$ \\
Ortaokul & 21 & $\% 21,0$ \\
Lise & 27 & $\% 27,0$ \\
Üniversite & 15 & $\% 15,0$ \\
\hline Toplam & 100 & $\% 100,0$ \\
\hline
\end{tabular}

Yeni kelimeler Ö(k)- kısmi ödünçleme, Ö(t)- tam ödünçleme, B- birleşik kelime, A- ad şeklinde yapı bakımından sınıflandırıldı ve bu kelimeler türetme biçimlerine göre sayıları tespit edildi ve oranları hesaplandı (Tablo 8).

\section{Bulgular ve yorum}

Saha araştırmalarında sosyal medyada kullanılan aşağıdaki kelimeler derlenmiştir:

Tablo 8.

\begin{tabular}{|c|c|c|c|c|}
\hline \multicolumn{5}{|c|}{ Sosyal Medyada Kullanılan Kelimeler ve Türetme Şekilleri } \\
\hline S.N. & Kelimeler & Anlamı & TDK & Türetme Biçimi \\
\hline 1 & face time & Görüntülü görüşmek & - & $\ddot{O}(\mathrm{t})<\operatorname{Ing}$. \\
\hline 2 & hashtag & $\begin{array}{l}\text { Belirli bir konuyu belirlemek ve ayrıştırmak } \\
\text { için kullanılmaktadır }\end{array}$ & - & $\ddot{O}(\mathrm{t})<\dot{\mathrm{In} g}$. \\
\hline 3 & kullanıcı adı & Sosyal medyada kullanılan takma ad & - & $\mathrm{B}(\mathrm{A}+\mathrm{A})$ \\
\hline 4 & gt atmak & $\begin{array}{l}\text { Sosyal medyada takip eden kişiyi takip etmek } \\
\text { (gt: geri takip) }\end{array}$ & - & $\mathrm{B}(\mathrm{A}(\mathrm{k})+\mathrm{A})$ \\
\hline 5 & rt'lemek & $\begin{array}{l}\text { Twitter'da atılan Tweet'i paylaşmak (rt: } \\
\text { retweet) }\end{array}$ & - & Ö $(\mathrm{k})<\dot{\mathrm{In} g}$. \\
\hline 6 & chatleşmek & Sosyal medyada mesajlaşmak, sohbet etmek & - & $\ddot{O}(\mathrm{k})<\operatorname{Ing}$ \\
\hline 7 & gif & Hareketli resim & - & Ö $(\mathrm{t})<\dot{\mathrm{I}} \mathrm{ng}$. \\
\hline 8 & offline & Çevrimdışı & - & $\ddot{O}(\mathrm{t})<$ İng. \\
\hline
\end{tabular}




\begin{tabular}{|c|c|c|c|c|}
\hline 9 & selfie & Özçekim & - & $\ddot{O}(\mathrm{t})<\dot{\text { Ing. }}$. \\
\hline 10 & touch ID & $\begin{array}{l}\text { Parmak izi okuma teknolojisi destekli } \\
\text { güvenlik sistemi }\end{array}$ & - & Ö$(t)<$ Ing. \\
\hline 11 & link & İlişim & + & A \\
\hline 12 & fake hesap & Sahte hesap & - & Ö $(\mathrm{k})<$ Ing \\
\hline 13 & PP & Profil fotoğrafi (profile picture: PP) & - & $\ddot{O}(\mathrm{t})<\dot{\text { Ing. }}$. \\
\hline 14 & online & Çevrimiçi & - & $\ddot{O}(\mathrm{t})<$ İng. \\
\hline 15 & görüldü atmak & $\begin{array}{l}\text { Sosyal medyadan gelen mesajı okuyup cevap } \\
\text { vermemek }\end{array}$ & - & $\mathrm{B}(\mathrm{E}+\mathrm{E})$ \\
\hline 16 & youtuber & Video çekerek youtube'a yükleyen kişi & - & $\ddot{O}(\mathrm{t})<\dot{\text { Ing. }}$. \\
\hline 17 & e-posta & Elektronik posta & + & A \\
\hline 18 & e-mail & Elektronik posta (e-mail, kökeni İng.) & + & A \\
\hline 19 & emoji & Şekil ve sembollerle gösterilen duygu hali & - & $\ddot{O}(\mathrm{t})<\dot{\text { Ing. }}$. \\
\hline 20 & takipçiler & Sosyal medyada ekli kişiler & - & $\mathrm{B}(\mathrm{A})$ \\
\hline 21 & like & Beğenmek & - & $\ddot{O}(\mathrm{t})<\dot{\text { Ing. }}$. \\
\hline 22 & beğeni & Güzel veya çirkin yargısını verdiren duygu & + & A \\
\hline 23 & unfollow & Takip etmeyi bırakmak & - & $\ddot{O}(\mathrm{t})<$ İng. \\
\hline 24 & follower & Takipçi sayısı & - & $\ddot{O}(\mathrm{t})<\dot{\text { Ing. }}$. \\
\hline 25 & takipten çıkarmak & Takip etmeyi bırakmak & - & $\mathrm{B}(\mathrm{A}+\mathrm{E})$ \\
\hline 26 & like atmak & Beğenmek & - & Ö $(\mathrm{k})<$ İng \\
\hline 27 & block & Engel & - & $\ddot{O}(\mathrm{t})<\dot{\text { Ing. }}$. \\
\hline 28 & snap atmak & Snapchat'te paylaşım yapmak & - & Ö $(\mathrm{k})<\dot{\mathrm{In} g}$ \\
\hline 29 & admin & $\begin{array}{l}\text { Sosyal medyada sayfa yöneticilerine verilen } \\
\text { ad }\end{array}$ & - & Ö$(\mathrm{t})<\dot{\mathrm{In}} \mathrm{g}$. \\
\hline 30 & etiketlemek & $\begin{array}{l}\text { Belirli bir konuyu belirlemek ve ayrıştırmak } \\
\text { için kullanılmakta }\end{array}$ & - & $\mathrm{B}(\mathrm{E})$ \\
\hline 31 & konum atmak & Bulunulan yeri paylaşmak & - & $\mathrm{B}(\mathrm{A}+\mathrm{E})$ \\
\hline 32 & bio & $\begin{array}{l}\text { Profile kendini tanıtmak için yazılan kısa } \\
\text { bilgi (bio: biyografi) }\end{array}$ & - & $\mathrm{B}(\mathrm{A}(\mathrm{k}))$ \\
\hline 33 & banlamak & Engellemek (İng. ban) & - & Ö $(\mathrm{k})<$ İng \\
\hline 34 & stalk & Birinin profilini incelemek & - & $\ddot{O}(\mathrm{t})<\dot{\text { Ing. }}$. \\
\hline 35 & dislike & Beğenmemek & - & $\ddot{O}(\mathrm{t})<\dot{\text { Ing. }}$. \\
\hline 36 & tweet & Twitter'da paylaşılan yazılar & - & $\ddot{O}(\mathrm{t})<$ İng. \\
\hline 37 & retweet & Atılan tweet'i paylaşmak & - & $\ddot{O}(\mathrm{t})<$ İng. \\
\hline 38 & $100 \mathrm{k}$ & 100 bin takipçisi olan & - & Ö $(\mathrm{k})<$ İng \\
\hline 39 & error & Hata & - & $\ddot{O}(\mathrm{t})<$ İng. \\
\hline 40 & story & 24 saatlik paylaşılan içerik & - & Ö $(\mathrm{t})<$ İng. \\
\hline 41 & paylaşım & Paylaşma işi & + & A \\
\hline 42 & post & Paylaşım & - & $\ddot{O}(\mathrm{t})<\dot{\text { Ing. }}$. \\
\hline 43 & engel atmak & Engellemek & - & $\mathrm{B}(\mathrm{A}+\mathrm{E})$ \\
\hline 44 & zumlamak & $\begin{array}{l}\text { Zumlamak, bir nesnenin görüntüsünü } \\
\text { büyütmek için objektifin odak uzakllğını } \\
\text { değiştirmek, yakınlaştırmak }\end{array}$ & + & $\mathrm{E}$ \\
\hline
\end{tabular}


$\mathbf{Z}$ generation of young people in social media usage patterns of neologisms a quantitative approach in the sample Kurklareli province center / Z. Şafak (p. 125-136)

$\begin{array}{lllll}45 & \text { sticker } & \text { (Sticker, ing.) çıkartma } & + & \text { A } \\ 46 & \text { özçekim } & \text { Selfie kelimesinin Türkçe karşılı̆̆ı } & - & \text { B(A) } \\ 47 & \text { DM } & \text { Sosyal medyada doğrudan mesaj } & - & \text { B(A(k)) } \\ 48 & \text { trendtopic } & \text { Twitter de en çok konuşulan konular, } & - & \text { Ö(t)<ìng. } \\ & & \text { en çok ilgi gören paylaşımlar } & - \\ 49 & \text { favlamak } & \text { Twitter de beğenmek (fav: favori) } & - & \text { B(E) } \\ 50 & \text { fake atmak } & \text { Olmayan bir şey ile kandırmak } & - & \text { Ö }(k)<\text { İng. }\end{array}$

\section{Kisaltmalar:}
B: birleşik kelime
A: ad
E: eylem
$\mathrm{A}(\mathrm{k})$ : kısaltılmış ad

Ö(t): tam ödünçleme $\quad$ Ö(k): kısmi ödünçleme İng.: İngilizce

Saha araştırmalarında tespit edilen kelimeleri yapı bakımından şu şekilde gruplandırmak mümkündür: Çevrimiçi TDK sözlügüne girmiş sözcükler (ad, eylem), çevrimiçi TDK sözlüğünde mevcut olmayan yeni kelimeler (tam ödünçleme, kısmi ödünçleme, kısaltılmış ad vs.), (Tablo 8), (Tablo 9).

Tablo 9.

Yeni Kelimeler ve Türk Dil Kurumunun Çevrimiçi Sözlüğüne Girmiş Kelimelerin Sayıları ve Oranları

\begin{tabular}{lccc} 
& Sayı & Oran \\
\hline $\begin{array}{l}\text { TDK çevrimiçinde tespit } \\
\text { kelimelerin sayısı ve oranı }\end{array}$ & 7 & $\% 14$ \\
$\begin{array}{l}\text { Yeni kelimelerin } \\
\text { (Neolojizmler) }\end{array}$ & sayısı ve oranı & 43 & $\% 86$ \\
\hline Toplam & 50 & $\% 100$ \\
\hline
\end{tabular}

Okullarda tespit edilen kelimelerin \%86'sının TDK çevrimiçi sözlüğünde mevcut olmadığı tespit edilmiş olup sadece \%14’ü TDK sözlüğünde bulunmaktadır (Tablo 8).

Tablo 10.

\begin{tabular}{lcc}
\hline \multicolumn{2}{l}{ Yeni Kelimeler (Neolojizmlerin) Türetilme Biçimleri: } & \\
\hline Türetme biçimi & Sayısı & Oran \\
$\mathrm{B}(\mathrm{A})$ & 2 & $\% 4,62$ \\
$\mathrm{~B}(\mathrm{~A}+\mathrm{A})$ & 1 & $\% 2,32$ \\
$\mathrm{~B}(\mathrm{~A}(\mathrm{k}))$ & 2 & $\% 4,62$ \\
$\mathrm{~B}(\mathrm{~A}(\mathrm{k})+\mathrm{A})$ & 1 & $\% 2,32$ \\
$\mathrm{~B}(\mathrm{~A}+\mathrm{E})$ & 3 & $\% 6,97$ \\
$\mathrm{~B}(\mathrm{E})$ & 2 & $\% 4,62$ \\
$\mathrm{~B}(\mathrm{E}+\mathrm{E})$ & 1 & $\% 2,32$ \\
Ö(k)<İng. & 8 & $\% 18,6$ \\
Ö(t)<İng. & 23 & $\% 53,4$ \\
\hline Toplam & 43 & \\
\hline
\end{tabular}


Sahadan derlenen yeni kelimelerin yapı bakımından durumları tablo 10'da verilmiştir; \%53,4 oranında $\ddot{O}(\mathrm{t})<$ İng. (İngilizceden tam ödünçlemeler), ikinci sırada \%18,6 oranında Ö $(\mathrm{k})<\dot{\text { Inng }}$ (İngilizceden kısmi ödünçlemeler), üçüncü sırada B(A+E) (Ad+ Eylemden oluşan) birleşik kelimeler tespit edilmiştir.

Tablo 10.

\begin{tabular}{|c|c|c|}
\hline \multicolumn{3}{|c|}{ Örneklemlerin Facebook Kullanım Sıklık Dağılımı } \\
\hline Kullanım & Slklık Dağılımı (f) & Oran \\
\hline 1. hiç & 58 & $\% 58,0$ \\
\hline 2. az & 32 & $\% 32,0$ \\
\hline 3. orta & 8 & $\% 8,0$ \\
\hline 4. çok & 2 & $\% 2,0$ \\
\hline Toplam & 100 & $\% 100,0$ \\
\hline \multicolumn{3}{|c|}{ Örneklemlerin Youtube Kullanım Sıklık Dağılımı } \\
\hline Kullanım & Siklık Dağılımı (f) & Oran \\
\hline 1. hiç & 3 & $\% 3,0$ \\
\hline 2. az & 11 & $\% 11,0$ \\
\hline 3. orta & 49 & $\% 49,0$ \\
\hline 4. çok & 37 & $\% 37,0$ \\
\hline Total & 100 & $\% 100,0$ \\
\hline \multicolumn{3}{|c|}{ Örneklemlerin WhatsApp Kullanım Sıklı Dağılımı } \\
\hline Kullanım & Slklık Dağılımı (f) & Oran \\
\hline 1. hiç & 1 & $\% 1,0$ \\
\hline 2. $a z$ & 6 & $\% 6,0$ \\
\hline 3. orta & 34 & $\% 34,0$ \\
\hline 4. çok & 59 & $\% 59,0$ \\
\hline Total & 100 & $\% 100,0$ \\
\hline \multicolumn{3}{|c|}{ Örneklemlerin Twitter Kullanım Sıklık Dağılımı } \\
\hline Kullanım & Sıklık Dağılımı (f) & Oran \\
\hline 1. hiç & 67 & $\% 67,0$ \\
\hline 2. az & 15 & $\% 15,0$ \\
\hline 3. orta & 10 & $\% 10,0$ \\
\hline 4. çok & 8 & $\% 8,0$ \\
\hline Toplam & 100 & $\% 100,0$ \\
\hline \multicolumn{3}{|c|}{ Örneklemlerin Facebook MessengerKullanım Siklık Dağılımı } \\
\hline Kullanım & Siklık Dağılımı (f) & Oran \\
\hline 1. hiç & 82 & $\% 82,0$ \\
\hline 2. az & 14 & $\% 14,0$ \\
\hline 3. orta & 4 & $\% 4,0$ \\
\hline Total & 100 & $\% 100,0$ \\
\hline
\end{tabular}


$\mathbf{Z}$ generation of young people in social media usage patterns of neologisms a quantitative approach in the sample Kırklareli province center / Z. Şafak (p. 125-136)

\begin{tabular}{lll}
\hline Kullanım & Sıklı Dağılımı (f) & Oran \\
1. hiç & 8 & $\% 8,0$ \\
2. az & 7 & $\% 7,0$ \\
3. orta & 16 & $\% 16,0$ \\
4. çok & 69 & $\% 69,0$ \\
\hline Toplam & 100 & $\% 100$ \\
\hline
\end{tabular}

Örneklem olarak seçilen öğrencilerin \%58’i Facebook’u hiç kullanmadıklarını belirttiler. Okullar arasında karşılaştırma yapıldığında Facebook'u en az kullanan okul Kırklareli İmam Hatip Lisesinde okuyan öğrencilerdir. En çok kullanan öğrenci oranı \% 2'dir (Tablo 10).

Örneklemlerden Youtube'u \%49'u orta ve \%37'si çok kullandıklarını belirttiler (Tablo 10). En çok kullanım Kırklareli İmam Hatip Lisesi ve Kırklareli Fen Lisesinde, en az kullanım ise Kocahıdır Mesleki Teknik Anadolu Lisesinde tespit edilmiştir.

Seçilen öğrencilerin \%59’u WhatsApp’ı çok, \%34’ü orta sılklkta kullandıkları ifade etmişlerdir. Araştırılan bütün liselerin WhatsApp sosyal medya uygulamasını yakın oranlarda kullandıkları görülmüştür (Tablo 10).

Örneklemlerin \%67'si Twitter sosyal medya uygulamasını hiç kullanmamaktadır (Tablo 10). Sadece \%8’i uygulamayı çok kullanmaktadır, bu uygulamayı çok olarak kullanan \%8 oranında öğrencinin farklı okullardan oldukları tespit edilmiştir.

Örneklem olarak seçilen öğrencilerin \%82'si Facebook Messenger’ı hiç kullanmadıklarını belirtiler (Tablo 10). Bu uygulamayı çok kullanan hiçbir örneklem mevcut değildir. Orta düzeyde kullanan ise 4 öğrenci tespit edildi. Bunlardan bir tanesi Kırklareli Atatürk Anadolu Lisesinde okumakta, üç tanesi de Kocahıdır Mesleki ve Teknik Anadolu Lisesinde okumaktadır.

Öğrencilerden \%69’u Instagram’ı çok kullandıkları tabloda görülmektedir (Tablo 10). En çok kullanan Kocahıdır Mesleki ve Teknik Anadolu Lisesinde okuyan öğrencilerdir, bu oran\% 16'dır.

Tablo 11.

\begin{tabular}{|c|c|c|c|c|c|c|c|}
\hline \multicolumn{8}{|c|}{ Tespit edilen kelimelerin yabancı dil ve Türkçe tercih edilme sıklıkları ve oranları } \\
\hline Kelimeler & $\begin{array}{l}\text { Anlamını } \\
\text { bilirim ve sık } \\
\text { kullanırım }\end{array}$ & $\begin{array}{l}\text { Anlamını } \\
\text { bilirim } \\
\text { bazen } \\
\text { kullanırım }\end{array}$ & ve & $\begin{array}{l}\text { Anlaminı } \\
\text { bilirim, fakat } \\
\text { kullanmam }\end{array}$ & $\begin{array}{l}\text { Anlamını } \\
\text { bilmem, } \\
\text { fakat } \\
\text { kullanırım }\end{array}$ & $\begin{array}{l}\text { Anlaminı } \\
\text { bilmem ve } \\
\text { hiç } \\
\text { kullanmam }\end{array}$ & $\begin{array}{l}\text { Anlamsal } \\
\text { Durum }\end{array}$ \\
\hline
\end{tabular}

\begin{tabular}{|c|c|c|c|c|c|c|c|c|c|c|c|}
\hline \multicolumn{2}{|c|}{ Siklık (f) } & \multicolumn{10}{|c|}{ Oran Siklık (f) Oran Siklık (f) Oran Siklık (f) Oran Siklık (f) Oran } \\
\hline hashtag & 20 & $\% 20,0$ & 28 & $\% 28,0$ & 32 & $\% 32,0$ & 2 & $\% 2,0$ & 18 & $\% 18,0$ & Aynı anlam \\
\hline etiketlemek & 58 & $\% 58,0$ & 34 & $\% 34,0$ & 6 & $\% 6,0$ & 1 & $\% 1,0$ & 1 & $\% 1,0$ & \\
\hline unfollow & 26 & $\% 26,0$ & 29 & $\% 29,0$ & 32 & $\% 32,0$ & o & $\% \mathrm{o}, \mathrm{o}$ & 13 & $\% 13,0$ & Aynı anlam \\
\hline $\begin{array}{l}\text { takipten } \\
\text { çıkarmak }\end{array}$ & 53 & $\% 53,0$ & 26 & $\% 26,0$ & 21 & $\% 21,0$ & o & $\% 0,0$ & o & $\% \mathrm{o}, \mathrm{O}$ & \\
\hline like & 73 & $\% 73,0$ & 14 & $\% 14,0$ & 13 & $\% 13,0$ & 0 & $\% 0,0$ & o & $\% 0,0$ & Aynı anlam \\
\hline like atmak & 74 & $\% 74,0$ & 13 & $\% 13,0$ & 13 & $\% 13,0$ & o & $\% 0,0$ & o & $\% \mathrm{o}, \mathrm{O}$ & \\
\hline Kurklareli Ünive & & $\begin{array}{l}\text { Edebiyat Fa } \\
\text { mü, Kayalı }\end{array}$ & $\begin{array}{l}\text { Ites } \\
\text { apü } \\
\text { sta }\end{array}$ & $\begin{array}{l}\text { rk Dili ve } \\
\text { urklareli/' } \\
\text { itor@rum }\end{array}$ & $\begin{array}{l}\text { Adres } \\
\text { lebiyat } \\
\text { RKIYY } \\
\text { de.com }\end{array}$ & $\begin{array}{l}\text { Adres } \\
\text { Kurklar } \\
\text { Turkisl } \\
\text { e-mail }\end{array}$ & ing & $\begin{array}{l}\text { y, Faculty } \\
\text { and Litera } \\
\text { melide.co }\end{array}$ & 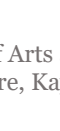 & $\begin{array}{l}\text { Scien } \\
\text { Camp }\end{array}$ & $\begin{array}{l}\text { epartment of } \\
\text { rrklareli/TURKEY }\end{array}$ \\
\hline
\end{tabular}




\begin{tabular}{lccccccccccc} 
beğenmek & 78 & $\% 78,0$ & 14 & $\% 14,0$ & 8 & $\% 8,0$ & 0 & $\% 0,0$ & 0 & $\% 0,0$ & \\
\hline post & 48 & $\% 48,0$ & 28 & $\% 28,0$ & 19 & $\% 19,0$ & 0 & $\% 0,0$ & 4 & $\% 4,0$ & Aynı anlam \\
paylaşım & 69 & $\% 69,0$ & 25 & $\% 25,0$ & 5 & $\% 5,0$ & 0 & $\% 0,0$ & 1 & $\% 1,0$ & \\
\hline selfie & 61 & $\% 61,0$ & 28 & $\% 28,0$ & 11 & $\% 11,0$ & 0 & $\% 0,0$ & 0 & $\% 0,0$ & Aynı anlam \\
özçekim & 41 & $\% 41,0$ & 23 & $\% 23,0$ & 34 & $\% 34,0$ & 1 & $\% 1,0$ & 1 & $\% 1,0$ & \\
\hline banlamak & 22 & $\% 22,0$ & 22 & $\% 22,0$ & 34 & $\% 34,0$ & 3 & $\% 3,0$ & 19 & $\% 19,0$ & Aynı anlam \\
engel atmak & 48 & $\% 48,0$ & 33 & $\% 33,0$ & 17 & $\% 17,0$ & 0 & $\% 0,0$ & 2 & $\% 2,0$ & \\
\hline
\end{tabular}

Sosyal medya uygulamalarında kullanılan kelimelerin Türkçe ve yabancı dil tercih edilirliği ile ilgili frekans sıklıkları ve oranları incelendiğinde (tablo 11) sosyal medya uygulamalarında Türkçe karşıllğı mevcut olan kelimelerin daha sık kullanıldıkları tespit edildi. Örneğin "paylaşım" \%69 oranında kullanılmış iken İngilizce karşılığı olan "post" kelimesi \%48 oranında örneklemler tarafından daha düşük oranda kullanılmaktadır. Bu genellemeye sadece "selfie" ve "özçekim" kelimeleri uymamaktadır. İngilizce olan selfie kelimesi \%61 oranında "özçekim" kelimesinden daha çok kullanıldığı tespit edildi. "Anlamını bilmem ve hiç kullanmam" maddesi altında daha çok yabancı dilden dilimiz giren kelimelerin olduğu tablo 15 görülmektedir. Like, like atmak, beğenmek kelimelerinin kullanım oranları sırasıyla \%73, \%74, \%78 oranında bir sıklı vardır, bu kelimelerin her üçünün birbirine yakın oranda kullanıldığını söylemek mümkündür.

Çalışmanın bu kısmında aynı sosyal medya uygulamalarında Twitter'da kullanılan kelimelerin ilgileşimleri incelenmiş olup veriler parametrik testler için gerekli şartları taşımadığından parametrik olmayan Spearman Sıra Farkları Korelasyonu (ilgileşim) Katsayısı SPSS 25 istatistik programında hesaplandi (Tablo 12).

\begin{tabular}{|c|c|c|c|}
\hline \multicolumn{4}{|c|}{ Tespit edilen kelimelerin yabancı dil ve Türkçe tercih edilme sıklıkları ve oranları } \\
\hline & rt'lemek & tweet & retweet \\
\hline rt'lemek & 1,000 &, 538 &, 582 \\
\hline tweet & 538 & 1,000 & ,807 \\
\hline retweet &, 582 & 807 & 1,000 \\
\hline
\end{tabular}

Sig. (1-tailed)=,o0o hesapland, bu durumda $\mathrm{p}=0,00 \quad \mathrm{p}<0,01$ düzeyinde anlamlı bir ilişki vardır. Öğrencilerin aynı sosyal uygulamaya ait kelimelerin kullanımında ilişki olup olmamasını ortaya koymak için yapılan Spearman Sıra Farkları Korelasyon işleminde pozitif yönde anlamlı düzeyde bir ilişki olduğu görülmektedir (tablo 12).

\section{Sonuç}

Çalışmadan elde edilen bilgilere bağlı kalınarak aşağıdaki çıkarımları sunmak mümkündür:

1- Sosyal medya aracılı̆̆ıla Türkçeye birçok yabancı kelime girmektedir. Bu kelimelerin Türkçe karşılıkları olmadığından gençler tarafından yoğun olarak kullanılmaktadır. Ayrıca çevrimiçi (internet) dilinin ve sosyal medya uygulamalarında kullanılan dilin İngilizce olması İngilizceden Türkçeye geçen kelimelerin artmasına ve çabuk benimsenmesine neden olmaktadır. 
2- Gençler tarafından kullanılan, aynı zamanda TDK çevrimiçi sözlüğünde mevcut olan bazı kelimelerin Türkçeleştirilmeden İngilizce yazılışıyla sözlüğe girdikleri görülmüştür; örneğin TDK çevrimiçi sözlüğünde stikır şeklinde değil de kelimenin Sticker olarak İngilizce yazılış şekliyle mevcut olduğu tespit edilmiştir.

3- Alan taramasında kayıt edilen 13 kelimenin Türkçe veya Türkçeleşmiş oldukları görüldü. Bu kelimeler tüm sözcüklerin \%26’sını oluşturmaktadır.

4- Örneklemler tarafindan kullanılan yeni kelimeler yapı bakımından incelendiğinde bu kelimelerin, $\mathrm{B}(\mathrm{A}), \mathrm{B}(\mathrm{A}+\mathrm{A}), \mathrm{B}(\mathrm{A}(\mathrm{k})), \mathrm{B}(\mathrm{A}(\mathrm{k})+\mathrm{A}), \mathrm{B}(\mathrm{A}+\mathrm{E}), \mathrm{B}(\mathrm{E}), \mathrm{B}(\mathrm{E}+\mathrm{E}), \quad \mathrm{O}(\mathrm{k})<$ Ing., Ö $(\mathrm{t})<$ Ing. dokuz şekilde türetildikleri ve kullanıldıkları tespit edilmiştir.

5- Aynı sosyal uygulamaları kullanan örneklemler uygulamalara ait kelimeler ile kullanım arasında birbirleriyle ilişkili pozitif bir ilgileşim olduğu, bu kelimelerin aynı uygulamalar sayesinde örneklemlerin sözcük dağarcığına girdikleri anlaşıldı.

\section{Kaynakça}

Altunbay, M., \& Bıçak, N. (2018). Türkçe Eğitimi Derslerinde "Z Kuşağı" Bireylerine Uygun Teknoloji Tabanlı Uygulamaların Kullanımı. ZfWT , 10 (1), 127-142.

Can, A. (2017). SPSS ile Nicel Veri Analizi. Ankara: Pegem akademi.

Erten, P. (2019). Z Kuşağının Dijital Teknolojiye Yönelik Tutumları. Gümüşhane Üniversitesi Sosyal Bilimler Enstitüsü Elektronik Dergisi , 190-202.

Kuyucu, M. (2014). Y Kuşağı ve Facebook: Y Kuşağının Facebook Kulllanım Alışkanlıkları Üzerine Bir İnceleme. Elektronik Sosyal Bilimler Dergisi , 13 (49-50), 55-83.

Moeschler, J. (1974). Aspects de la néologie sémantique. La néologie lexicale. Langages , 6-19.

Özden, A. T. (2019). Pozitif Algının ve Tüketici Karar Verme Tarzlarının Y ve Z Kuşakları. Gazi İktisat ve İşletme Dergisi , 1-20.

Öztürk, M. C., İspir, B., Birsen, H., Özata, F. Z., Bayraktutam, G., Öztürk, M. C., et al. (2013). Dijital İletişim ve Yeni Medya. Eskişehir: Anadolu Üniversitesi.

Şafak, Z. (2018). Fransızca ve Türkçede Akıllı Telefon Bağlamında Yeni Sözcük Kullanımına (Neolojizm) Yapısal Bir Yaklaşım . Namık Kemal Üniversitesi Sosyal Bilimler Enstitüsü Yayaınlanmamış Yüksek Lisan . Tekirdağ.

\section{Çevrimiçi kaynaklar}

Türk Dil Kurumu Çevrimiçi Sözlük (http://sozluk.gov.tr/) 17.07.2019 